\title{
(2)
}

Francesc Granell Trias*

\section{EL SISTEMA ECONÓMICO INTERNACIONAL EN 2016}

En 2016 seguimos arrastrando muchos de los problemas que comenzaron con la crisis iniciada en 2007. Las tentaciones proteccionistas hacen que la globalización esté perdiendo un cierto ritmo. El 2016 ha visto el ascenso de populismos derivados del hecho de que la economía aún no ha recuperado los niveles que tenía antes de la Gran Recesión de 2007 con el deterioro del estado del bienestar en muchos países, lo cuál ha gestado una rebelión ciudadana en muchos de ellos. El terrorismo yihadista y el conflicto de Oriente Medio han seguido generando flujos descontrolados de refugiados y migrantes hacia Europa lo cual ha ocasionado muchos problemas en la Unión Europea y ha sido uno de los elementos que ha estado en la base del deseo de Gran Bretaña de salir de la UE (brexit). España, con Gobierno en funciones durante 11 meses, ha figurado entre los miembros no permanentes del Consejo de Seguridad de Naciones Unidas.

Palabras clave: crisis económica mundial, Organización Mundial del Comercio, Fondo Monetario Internacional, Objetivos de Desarrollo Sostenible, Unión Europea, cambio climático, populismo, terrorismo, refugiados.

Clasificación JEL: F02, F10, F13, F21, G15, E40, K33, L80, O10.

\section{Introducción}

El sistema económico internacional se está resintiendo del escaso ritmo de desarrollo que se ha registrado en la economía mundial, lo cual ha dado lugar a la aparición de proteccionismos y populismos en muchos países, acompañados de fenómenos de terrorismo y de rebrotes de nacionalismo que no se producían con la intensidad que en el 2016 se han producido.

\footnotetext{
* Catedrático emérito de Organización Económica Internacional de la Universidad de Barcelona y miembro de número de la Real Academia de Ciencias Económicas y Financieras. Este artículo forma parte de la serie que con el mismo título viene publicando el autor en el Boletín Económico de ICE, por estas fechas, anualmente desde 1977.

Versión de diciembre de 2016
}

En estas páginas se hará un repaso de los temas que han estado más presentes en el sistema económico internacional a lo largo del año.

En un primer apartado veremos cuál ha sido el crecimiento de la economía mundial y de los principales países. En un segundo apartado veremos la situación del comercio mundial y de las integraciones regionales con los riesgos proteccionistas que están poniendo en peligro alguno de los logros que había conseguido la Organización Mundial del Comercio (OMC) para impulsar el comercio internacional a mayor ritmo que la economía mundial en su conjunto. En un tercer apartado se verá $D$ 
la situación de los pagos internacionales con el creciente papel de China. El cuarto apartado glosará los Objetivos de Desarrollo Sostenible lanzados para el periodo 20162030. En el quinto se verá la situación por la que atraviesa la Unión Europea (UE) agobiada por la avalancha de refugiados de los países del Mediterráneo y Medio Oriente y los peligros derivados de una futura salida de Gran Bretaña de la Unión Europea (brexit) una vez culmine el proceso de negociación previsto en el artículo 50 del Tratado de la UE. Por último, y antes de la bibliografía, veremos cómo se ha situado España en el contexto del sistema económico internacional en el 2016, año en que se han cumplido 30 años de la participación de España en la Unión Europea, y en que España ha formado parte del Consejo de Seguridad del Consejo de Seguridad de las Naciones Unidas.

\section{Una economía mundial en crecimiento lento}

De acuerdo con las últimas estimaciones del Fondo Monetario Internacional (FMI), dadas a conocer en el World Economic Outlook, la economía mundial habrá crecido en 2016 un 3,1 por 100 (la OCDE estima un 2,9 por $100)$ pero las economías avanzadas solamente lo han hecho en un 1,6 por 100, mientras que los países en desarrollo lo habrán hecho en un 4,2 por 100 .

El relativamente lento crecimiento de China, la caída del PIB de Rusia y de los países de la OPEP -por los bajos precios del petróleo- y los bajos precios de la mayoría de las materias primas, así como el insuficiente crecimiento de la eurozona han condicionado los equilibrios y desequilibrios económicos mundiales.
De acuerdo con el Global Wealth Report de Credit Suisse, los que tienen activos superiores a los 2.222 USD solo son la mitad de la población mundial, los que tienen activos superiores a 71.560 USD, figuran ya entre el 10 por 100 de los más ricos y los que tienen activos de más de 744.400 USD representan el 1 por 100 de la población mundial.

En un cuadro de estas características ha creado estupefacción el contenido de los Papeles de Panamá (3 de abril) que han puesto al descubierto a muchos evasores fiscales, lo cual ha rearmado a la OCDE a través de la iniciativa BEPS (Base Erosion and Profit Shifting) 2016-2020, al Grupo de Acción Financiera Internacional (GAFI) y a la UE para evitar la «doble no imposición internacional» derivada del fraude, para luchar contra las prácticas de algunos países para atraer negocios extranjeros y multinacionales (deseo del que no han escapado países europeos como Irlanda, Holanda, Luxemburgo y Chipre) y para hacer difícil el blanqueo de dinero negro.

El año 2016 ha acabado, además, con una serie de cuestiones e incertidumbres que pueden alterar muchas cosas en un próximo futuro:

- La puesta en marcha de la Administración norteamericana encabezada por el $45^{\circ}$ presidente de Estados Unidos, Donald Trump, tras su sorprendente victoria electoral del 8 de noviembre de 2016 con sus ideas proteccionistas y nacionalistas.

- El resultado del referéndum británico sobre la salida del Reino Unido de la Unión Europea (brexit).

- El continuo debate entre keynesianos y hayekianos respecto a la política económica a seguir para salir de la situación de la Gran Recesión iniciada en 2007 y que tiene algunos puntos en común con la Gran Depresión de 1929. 
- El terrorismo en sus diferentes manifestaciones y su futuro a medida que el Estado Islámico vaya siendo derrotado y se produzca una «metástasis» de sus militantes para ejecutar acciones terroristas por todo el mundo.

- Las amenazas al estado del bienestar por los déficits presupuestarios y el empobrecimiento que padecen muchos grupos sociales.

- El incremento del peso mundial de la China de Xi Jinping, con reivindicaciones sobre su mar adyacente y un creciente enfrentamiento con Estados Unidos.

- El deseo del presidente ruso Putin de recuperar el peso que tuvo la Unión Soviética antes de su desaparición en 1991.

- La creciente importancia de las ciudades dentro de la economía mundial.

- Los peligros de una recaída de la economía mundial.

- El futuro de la lucha contra el cambio climático en la era post-Obama.

Todas estas cuestiones están llevando a rebeliones ciudadanas que en Latinoamérica han hecho caer a muchos Gobiernos de izquierdas y que en que en países desarrollados han generado movimientos populistas estimulados, además, por la gran afluencia de inmigrantes de países del Sur, países en conflicto y Estados fallidos que algunos asocian al desarrollo del terrorismo islamista y a atentados de grupos radicales (París, Niza, Bruselas Londres, Berlín, Estanbul, El Cairo, etcétera).

Ante la crisis, la situación ha llegado a tal extremo que el Fondo Monetario Internacional (FMI) y la Organización para la Cooperación y el Desarrollo Económicos (OCDE) están solicitando aumentos de gasto público para estimular el crecimiento, conseguir un desarrollo más inclusivo y evitar, con ello, que los niveles de democracia alcanzados en los últimos años sean substituidos por movimientos contestatarios y antisistema, y por manifestaciones, huelgas y hasta atentados. Tanto el Banco Mundial como la OCDE y el G20 han insistido en la necesidad de que todos los países supriman la burocracia para crear empresas y así conseguir crear empleos.

Los BRICS, que tanto crecieron hace unos años, están pasando por situaciones delicadas. Brasil, pese a haber organizado los Juegos Olímpicos de Río (5-21 de agosto) ha experimentado un retroceso del 3,4 por 100 de su PIB con mucha corrupción y con impeachment de la presidenta Dilma Roussef. China solo ha crecido al 6,7 por 100 y el PIB de Rusia ha caído en un 0,8 por 100 por los bajos precios del petróleo y las sanciones comerciales aplicadas por la UE como consecuencia de la ocupación de Crimea. Sudáfrica muestra una economía estancada y una tasa de desempleo superior al 25 por 100 . Solamente India se ha salvado de esta situación general de los BRICS con un crecimiento del 7,6 por 100 . Pese a ello, los BRICS han puesto en marcha su propio banco de desarrollo con sede en Shangai (New Development Bank: vid. Infra).

Una situación especialmente dramática ha sido la de Venezuela con una caída del PIB de más del 14 por 100 y con un déficit presupuestario de más del 24 por 100, cuestiones que han determinado una fuerte oposición a la política económica y monetaria seguida por la Administración del sucesor de Chaves, Nicolás Maduro, y muchos disturbios.

En todo este contexto de crecimiento lento, abre esperanzas de futuro la Cuarta Revolución Industrial (con su Internet de las cosas, su inteligencia artificial, sus robots, sus fotocopiadoras 3D y su división del trabajo) que fue especialmente saludada y analizada en la reunión del Foro Económico Mundial celebrada en Davos en enero de 2016. 


\section{El sistema comercial mundial}

Según estimaciones de la Organización Mundial de Comercio, el comercio internacional habrá crecido en el 2016 un 1,7 por 100 en valor en dólares, cuando en 2015 había caído, en términos de dólares en un 13,8 por 100 desde lo que había sido su récord histórico de 2014. Estas cifras demuestran que el comercio mundial ha crecido menos, en 2015 y 2016, que el producto mundial bruto, cosa a la que no estábamos acostumbrados en todos los años en que se iba ampliando la globalización y en que el comercio crecía más rápidamente que el producto mundial por el peso de las transacciones intragrupo de las multinacionales y el desarrollo de las cadenas de valor en el tablero mundial.

La apertura de la ampliación del Canal de Panamá (26 de junio) y la quiebra de la séptima empresa naviera mundial (la coreana Hanjin) por la caída de la demanda china y los bajos precios de muchas materias primas han marcado elementos técnicos a la situación del sistema comercial mundial como también lo ha sido la aprobación de una serie de enmiendas al Sistema Armonizado de Clasificación Arancelaria que ahora pasa a tener 5.386 posiciones de 6 dígitos, lo cual obligará, esto sí, a renegociar ciertas consolidaciones y concesiones entre los miembros de la OMC que se habían pactado con las nomenclaturas en vigor que se habían venido aprobando desde 1992. En este contexto cobra interés, además, el deshielo durante una parte del año del Ártico por el cambio climático, lo cual crea posibles rutas marítimas alternativas para el comercio entre el Atlántico y el Pacífico.

En el 2016 se ha visto una caída de los precios del petróleo que llegó a los 27,88 dólares el barril en enero (había estado en los
115 dólares a mediados de 2014), cuando se levantó el embargo a la exportaciones iraníes y cuando el fracking norteamericano alcanzó sus máximos niveles. Solo a finales del año se ha recuperado el precio hasta los 55 dólares el barril como consecuencia del acuerdo entre los países de la Organización de Países Productores de Petroleo (OPEP) (30 de noviembre) de reducir su producción hasta los 32,5 millones de barriles diarios, retirando del mercado 1,2 millones diarios y con el compromiso, además, de otros países productores de retirar otros 600.000 barriles diarios (Rusia aportará una reducción de 300.000).

El café y el cobre han visto caer su cotización en un 25 por 100 y solamente el azúcar ha mostrado una tendencia positiva. De todas formas, el índice The Economist nos muestra que los precios no se han recuperado aún de los precios relativos que se alcanzaron antes de la Gran Depresión de 2007, con la excepción, ciertamente, del oro que se ha constituido en un valor refugio ante las tormentas monetarias y financieras en los momentos en que el dólar ha caído.

En el plano multilateral, Roberto Carvalho de Azevedo ha visto avalada su continuidad al frente de la OMC gracias a los relativamente buenos resultados de la $X$ Conferencia Ministerial de la entidad celebrada en Nairobi a finales de 2015, en donde consiguió que Brasil y la UE pactaran avances en relación a subvenciones a la exportación, créditos a la exportación, empresas comerciales de estado y ayuda alimentaria, culminando un proceso iniciado en la IX Conferencia Ministerial de la OMC celebrada en Bali en 2013 y tras haber conseguido ciertos avances en las negociaciones de un Acuerdo Plurilateral sobre Comercio de Bienes Medioambientales, y un Acuerdo sobre Comercio de Servicios (TISA), $\triangleright$ 
en la liberalización del comercio electrónico y en tecnologías de la información (ITA).

Sin embargo, la Ronda de Doha lanzada por la OMC en 2001 sigue sin conseguir avances significativos y, en cambio, sobre el plano comercial estamos asistiendo a avances e iniciativas de carácter regional que están relativizando la importancia del sistema multilateral de comercio que había marcado el sistema mundial desde la creación del predecesor de la OMC: el Acuerdo General sobre Aranceles Aduaneros y Comercio (GATT).

De todas maneras, afortunadamente, en el World Tariffs Profiles de 2016, editado por la OMC, la Conferencia de las Naciones Unidas sobre Comercio y Desarrollo (UNCTAD) y el Centro de Comercio Internacional UNCTAD/ WTO (ITC) no se observan aumentos significativos de los aranceles como ocurriera durante la Gran Depresión de 1929, aunque la OMC sí ha detectado que en la primera parte de 2016 los Estados miembros establecieron 154 nuevas barreras al comercio y medidas de defensa comercial de carácter diverso (derechos antidumping y antisubvención, sobre todo para frenar ciertas exportaciones chinas).

De cualquier modo, lo que ha recabado una mayor atención en relación al sistema comercial mundial a lo largo de 2016 ha sido, como se ha dicho, la cuestión de las integraciones regionales y de las megaintegraciones (con participación de al menos dos de los grandes del comercio mundial). En teoría, tales arreglos regionales son un second best que estimulan el comercio mundial hasta que se llegue a una liberalización mundial general, pero que en la práctica suponen un serio atentado al multilateralismo, puesto que desde la concepción del GATT, a finales de la Segunda Guerra Mundial, las uniones aduaneras y las zonas de libre comercio eran excepciones a la cláu- sula de la nación más favorecida y no eran lo normal, como sucede hoy, en que la mayoría de los miembros de la OMC protagoniza alguna unión de carácter regional.

Entre las megaintegraciones hay que destacar el Trans Pacific Partnership (TPP) firmado, tras siete años de negociaciones, en Auckland (3 de febrero) por Australia, Brunei, Canadá, Chile, Japón, Malasia, México, Nueva Zelanda, Perú, Singapur, Vietnam y Estados Unidos y actualmente en avanzado estado de ratificación (Japón lo ha hecho el 9 de diciembre) pero que actualmente queda en la incertidumbre por las declaraciones del presidente electo Trump de que Estados Unidos prefiere arreglos bilaterales a arreglos plurilaterales.

La segunda gran megaintegración, ya en su decimotercera ronda de negociación, es la que se está intentando hacer avanzar entre Estados Unidos y la UE. Se trata de la Asociación Transatlántica de Comercio e Inversiones (TTIP) que debería unir a los dos asociados en torno a tres grandes pilares: acceso a los mercados recíprocos con reducciones arancelarias y medidas de facilitación importexport, armonizaciones regulatorias y reglas globales, entre las que hay que resaltar el controvertido tema de la creación de un tribunal arbitral para solventar las disputas entre multinacionales y Estados. La UE ha defendido que con el TTIP no se menoscabará el estado del bienestar europeo ni se rebajarán los estándares laborales, medioambientales y alimentarios europeos pero lobbies antisistema y sindicatos (con numerosas manifestaciones y desórdenes públicos) han conseguido bloquear el proceso negociador alegando secretismo y desconfianza en los resultados. Si a ello añadimos que el presidente electo Trump tampoco está a favor de culminar el TTIP, puede afirmarse, a finales del 2016, que el ambicioso $D$ 
proyecto inicial que se ha venido impulsando desde febrero de 2013 tiene un futuro incierto.

En el plano regional hay que mencionar el proyecto de Economic Community de ASEAN con un impulso (desde enero de 2016) para ir hacia un mercado único de 625 millones de habitantes formado por Indonesia, Malasia, Filipinas, Singapur, Tailandia, Brunei, Vietnam, Laos, Myanmar y Camboya como última fase del pacto de los cinco miembros iniciales del ASEAN de Bangkok de 1967. La idea es hacer una integración tipo UE aunque las presiones y la influencia china sobre Filipinas y Tailandia, para apoyar la posición de Pekín ante el rechazo por el Tribunal Internacional de la Haya sobre las reclamaciones sobre el Mar de China, pueden poner en peligro el futuro del proyecto ASEAN.

En Latinoamérica el 2016 ha visto avances significativos en la integración entre los países de la Alianza del Pacífico (México, Colombia, Perú y Chile) que han hecho entrar en vigor, el 20 de junio, su Protocolo Comercial estableciendo el libre comercio para el 92 por 100 de los productos, encaminándose, además, a una integración profunda que estimule los encadenamientos productivos a través de la libre circulación de bienes, así como la libre circulación de capitales, servicios y personas. El esquema ha sido condenado por el presidente boliviano Evo Morales porque, según él, la Alianza del Pacífico está en la línea del Consenso de Washington patrocinado por los Estados Unidos. La realidad es que estos países están creciendo más rápidamente que la economía mundial, que el conjunto de los países latinoamericanos lastrados por las crisis brasileña y argentina (tras pagar 9.300 millones de dólares a los tenedores de bonos «voltors»). La Alianza del Pacífico, con sus 218 millones de habitantes, está recabando mucha atención del mundo siendo ya 49 los países que mantienen observadores ante ella.

Mercosur, en cambio, ha experimentado en 2016 la penosa experiencia de tener que suspender de membresía a Venezuela (2 de diciembre) por no incorporar las normas a las que se había obligado en su protocolo de adhesión al grupo, producido cuando, a diferencia de la situación actual, todos sus miembros (menos Paraguay que obstaculizó el ingreso de Venezuela hasta 2013) estaban dirigidos por Gobiernos que simpatizaban con la Venezuela chavista que había firmado su incorporación a Mercosur en 2006.

\section{Los pagos internacionales y el papel de China en el FMI}

El sistema monetario internacional ha sufrido de vaivenes monetarios de diferente índole a lo largo de 2016, aunque se han evitado las restricciones cambiarias que hubieran resultado muy perjudiciales para la globalización. Los tipos de interés han permanecido cercanos al 0 por 100 y la inflación ha sido baja por los bajos precios del petróleo.

El rublo ha estado débil por la caída del precio del petróleo, las reformas económicas lanzadas por Putin y las sanciones europeas por la invasión de Crimea.

El dólar acaba el 2016 muy fuerte como consecuencia de que la economía norteamericana está yendo mejor (lo cual puede aún mejorar si Trump pone en marcha las rebajas fiscales prometidas en su campaña electoral) y como consecuencia, también, de que la presidenta de la Reserva Federal norteamericana (FED), Janet Yellen, había anunciado ya en el Simposio Anual de Jackson Hole (18 de agosto) que la FED subiría los tipos de interés $D$ 
antes del final del 2016 (debido a la mejora de la situación económica y al descenso del desempleo); cosa que, efectivamente, se hizo en la reunión de la FED del 14 de diciembre incrementando en un cuarto de punto el tipo de interés, con perspectivas, además, de nuevos incrementos en 2017. Ello generará, sin duda, un encarecimiento del servicio de la deuda de los países endeudados.

La libra esterlina acaba en 2016 a su nivel más bajo como consecuencia de las incertidumbres que ha generado, entre los operadores económicos de la City, el resultado favorable a la salida del Reino Unido de la UE en el Referéndum del 23 de mayo. El Banco de Inglaterra disminuyó sus tipos de interés del 0,5 al 0,25 por 100 el 4 de agosto, al tiempo que anunciaba un programa de compra de bonos corporativos y subasta de liquidez con objeto de estimular el crédito y evitar una caída fuerte de la economía por las perspectivas del brexit.

El Gobierno italiano del nuevo primer ministro Paolo Gentiloni ha tenido que rescatar, el 28 de diciembre, al Banco Monte dei Paschi di Siena (la más antigua de las instituciones financieras del mundo) para evitar el efecto sistémico que la caída del tercer banco de Italia hubiera producido. Ello se hizo necesario después de que el banco fuera incapaz de recapitalizarse privadamente desde que los stress test del BCE pusieran de manifiesto la limitada solvencia de la entidad. Los accionistas y bonistas deberán participar en las pérdidas de acuerdo con las reglas europeas sobre rescate de bancos. Al mismo tiempo la Comisión Europea deberá evaluar el impacto que el desembolso que finalmente sea necesario -dentro del paquete de hasta $\mathbf{2 0 . 0 0 0 ~ m i l l o n e s ~ d e ~ e u - ~}$ ros aprobado por el Parlamento italiano- vaya a tener sobre el déficit de las finanzas italianas en relación con el Plan de Estabilidad y Crecimiento, y en la confianza de que esta intervención devuelva la estabilidad al sistema bancario italiano.

En relación a la eurozona hay que decir que el Banco Central Europeo ha seguido manteniendo la política que anunció en 2012 de hacer todo lo posible para sostener el euro. Así, ha seguido con su programa de compra de títulos que desde el anuncio del 10 de marzo de 2016 pasó a establecerse en una cuantía mensual de 60.000 millones de euros, con inclusión de bonos corporativos y no solo de deuda pública o semipública, como había venido siendo, al tiempo que ha rebajado del $-0,3$ al -0,4 la facilidad de depósito, aumentándose del 33 al 50 por 100 el volumen de compras a títulos de un mismo emisor. Complementariamente, el BCE lanzaba una nueva ronda de préstamos a la banca a tipos de interés bajos (Long Term Refinancing Operations -LTRO-) con objeto de evitar la caída de la oferta monetaria en un tiempo de crisis. El 7 de diciembre el BCE decidió prorrogar la compra de bonos hasta diciembre de 2017, en vez de lo previsto que era hasta marzo, si bien desde abril de 2017 rebajará las compras mensuales de 80.000 millones a 60.000 millones de euros. Con ello y desde marzo de 2015 en que -pese a las reticencias alemanas- empezaron las compras, el BCE habrá inyectado un total de 2,3 billones de euros, con lo que su balance alcanza el 33 por 100 del PIB de la eurozona, mientras que el balance de la FED respecto al PIB norteamericano solamente supone el 25 por 100, muy por detrás, por cierto, de lo que supone tal relación en Japón ( 90 por 100 para tratar de reactivar la economía) y en Suiza (93 por 100 por compra de divisas para evitar la sobrevaloración del franco).

En otro orden de cosas y pasando a la evolución del Sistema Monetario Internacional $D$ 
conviene recordar que después de años de espera, los Estados Unidos aceptaron, finalmente, la $7^{\mathrm{a}}$ Revisión del Convenio Constitutivo del FMI y el decimocuarto aumento general de sus cuotas, cosa que le debe permitir atender a las necesidades de apoyo a los países con problemas de balanza de pagos, inclusive a Grecia que tiene ya otorgados dos planes de rescate y está en negociaciones para un tercero. El hecho de que el Gobierno de Tsipras se resista a aceptar las condicionalidades del ajuste exigido por el FMI, el BCE y la Comisión Europea para que Grecia pueda seguir manteniéndose en el euro está haciendo difícil que el tercer rescate tire adelante.

En este aumento de cuotas se ha reafirmado el papel que China, primer exportador mundial y segundo acreedor de los Estados Unidos tras Japón, tiene en el sistema mundial al pasar a tener la tercera cuota del FMI en cuantía (6,09 por 100 del total de los derechos de voto) tras las de Estados Unidos (16,54 por 100 del total) y Japón (6,16 por 100) y por delante, ahora ya, de las cuotas de Alemania (5,33 por 100), Francia (4,04 por $100)$, Rusia (2,60 por 100) y Arabia Saudí $(2,02)$, países todos ellos que pueden nombrar directamente al director ejecutivo entre los 24 componentes del mismo, mientras que el resto de miembros del Fondo deben estar agrupados para alcanzar mayor peso que el que tienen individualmente para poder nombrar un director ejecutivo. España, por ejemplo, tiene ahora una cuota que alcanza el 2 por 100 del total y se agrupa con 8 países latinoamericanos (México, Venezuela y países centroamericanos) para poder tener el representante de todos en el Directorio.

Desde el 1 de octubre de 2016 el renmimbiyuan chino ha pasado a ser una de las cinco divisas de referencia en la cesta del derecho especial de giro (DEG) que pasa a estar integrado en un 41,73 por 100 de su valor por el dólar, en un 30,93 por 100 por el euro, en un 10,92 por 100 por el yuan, en un 8,33 por 100 por el yen y en un 8,09 por 100 por la libra esterlina.

Así, y aunque China ha perdido a favor de Japón la posición de principal financiador de la deuda externa de los Estados Unidos, que había mantenido durante los últimos 8 años, gana presencia en el FMI a pesar de haber visto caer sus reservas al tener que echar mano de ellas para evitar la caída del yuan y tras haber establecido limitaciones para la repatriación de beneficios a las empresas extranjeras instaladas en China.

Este ascenso de China en al plano financiero internacional se ha visto acompañado por la puesta en marcha -por primera vez en la historia por impulso de Pekín- de dos nuevos bancos de desarrollo: el Nuevo Banco de Desarrollo, concebido inicialmente como banco de los BRICS, en 2012, cuyos accionistas son los cinco BRICS, con participación igual del 20 por 100, con sede en Shangai y que ha concedido sus primeros créditos en julio de 2016. Y el ambicioso proyecto del nuevo Banco Asiático de Inversión en Infraestructuras, con sede en Pekín, con participación de 57 países y un fuerte predominio de China en su capital con un 30,37 por 100 de total, seguido por India, Rusia, Alemania y Corea del Sur. Este banco se diseñó inicialmente para disminuir el poder que sobre las inversiones de infraestructuras ejercen Estados Unidos (a través del Banco Mundial con sede en Washington) y Japón (a través del Banco Asiático de Desarrollo con sede en Manila). Por esta razón los Estados Unidos acogieron con reticencias el proyecto chino, pero progresivamente se han ido incorporando a él países occidentales $\triangleright$ 
interesados en participar en los importantes proyectos de infraestructura que se van a financiar y que se han iniciado con un proyecto energético en Bangladesh y tres proyectos -en cooperación con el Banco Asiático de Desarrolloen Indonesia, Pakistán y Tayikistán. El propio presidente del Banco Mundial, el norteamericano de origen coreano Jim Yong Kim, ha saludado la nueva institución financiera como complementaria y no competidora en relación a los esfuerzos de financiación de infraestructuras y algo parecido han declarado representantes de la Administración Obama cerrando, así, la discusión política con que se había acogido la iniciativa china impulsada por su alta disponibilidad de reservas de cambio y por el hecho -seguramente anecdótico pero interesante- de que tras recibir una condonación de deuda de 40 millones por parte de Pekín, Zimbabwe ha adoptado el yuan como moneda de referencia.

También reseñar que los 5 países de la Comunidad de África del Este (Kenia, Uganda, Tanzania, Burundi y Ruanda) han decidido ir avanzando hacia una unión monetaria que debe ser completada en 2024. Con ello serán cuatro las uniones monetarias existentes en África: la de la Unión Económica y Monetaria del África del Oeste (UEMOA) desde 1994, la de Sudáfrica, Namibia, Swazilandia y Lesotho desde 1986 y la del África Central con el Franco CFA respaldado por el Tesoro francés.

En este apartado de las relaciones monetarias y financieras es preciso mencionar la preocupación creciente manifestada por la OCDE, el G7 (cumbre en Ise-Shima el 26-27 de mayo), el G20 (Cumbre en Hangzhou el 4-5 de septiembre), el BCE, la Comisión Europea y muchos países individualmente en relación al fraude, la evitación y la evasión fiscal internacionales que, se calcula, alcanza los 70.000 millones de dólares que es más, por cierto, de lo que se emplea en lo usado para asistir a refugiados, migrantes y desplazados en todo el mundo. Se ha tratado de evitar que en el mundo haya «agujeros fiscales negros» y hasta, en un intento por rebajar los tráficos ilegales, el BCE decidió el 5 de mayo dejar de imprimir billetes de 500 euros a partir de 2018. Este es un esfuerzo complejo pues hay países que ofrecen una fiscalidad muy baja y otros que son reticentes a comunicar las cuentas de sociedades ficticias, tal como se puso de manifiesto con el escándalo de los papeles del bufete Mossak-Fonseca de Panamá, destapado el 3 de abril, y que puso al descubierto cuentas millonarias y sociedades ficticias de personalidades económicas y políticas de todo el mundo.

\section{Los Objetivos de Desarrollo Sostenible (ODS)}

Teniendo en cuenta que las inversiones internacionales y las remesas de emigrantes rebasan con mucho las cifras siempre estancadas de la Ayuda Oficial al Desarrollo (AOD), que no hay manera de que llegue a alcanzar el objetivo del 0,7 por 100 que se viene sosteniendo como esiderátum desde el informe Pearson de 1970, el Comité de Ayuda al Desarrollo de la OCDE y las iniciativas sobre efectividad de la Ayuda al Desarrollo en los foros de Roma (2003), París (2005), Accra (2008) y Busán (2011) se concentran ahora más en aspectos cualitativos que en aspectos cuantitativos de la ayuda, sin que ello haga dejar de lado las reivindicaciones de los países pobres respecto a su deseo de recibir más ayuda tras las Conferencias sobre $\mathrm{Fi}$ nanciación del Desarrollo. 
Tales aspectos cualitativos tratan de hacer avanzar las ideas de apropiación, alineación, armonización, el enfoque de resultados y la responsabilidad compartida de donantes y beneficiarios.

Tras la decimocuarta sesión de la Conferencia de las Naciones Unidas sobre Comercio y Desarrollo (UNCTAD XIV), celebrada en Nairobi del 17 al 22 de julio, tras las promesas recibidas para adaptarse hacia una economía verde en la Conferencia sobre el Cambio climático de París en diciembre de 2015 y, sobre todo, tras el lanzamiento por la Asamblea General de las Naciones Unidas de septiembre de 2015 de los 17 Objetivos de Desarrollo Sostenible con sus 169 metas, los aspectos cualitativos de la ayuda han dado un paso adelante.

A lo largo de 2016 han sido varios los países que han puesto en marcha programas nacionales para avanzar hacia los Objetivos del Milenio como México, y son numerosas las conferencias y acciones llevadas adelante por el Programa de las Naciones Unidas para el Desarrollo, diferentes agencias de la familia de las Naciones Unidas como Unesco, FAO o Unicef $\mathrm{o}$ donantes individuales para implementar la consecución de los ODS. Ello ha llevado a las Naciones Unidas a aprovechar los días especiales dedicados a temas asociados a los ODS para sensibilizar y canalizar acciones de la Secretaría General y de las Agencias, así como las ONG y los embajadores de Buena Voluntad de las agencias en relación a los respectivos ODS. Algunos ejemplos de celebraciones y actuaciones ligadas a los 17 objetivos durante 2016 han sido, según la numeración de los ODS, los siguientes:

1. Fin de la pobreza en todas sus formas: Día Internacional sobre la Erradicación de la Pobreza (17 de octubre) con acciones del Banco Mundial, el PNUD y apoyo de las ONG.
2. Hambre cero y promoción de la seguridad alimentaria con el impulso de, sobre todo, la Organización de las Naciones Unidas para la Agricultura y la Alimentación (FAO) y el Programa Mundial de Alimentos (PAM) con el Día Internacional de la Alimentación (16 de octubre) y el Día del Agua (22 de marzo).

3. Salud y bienestar de las poblaciones con un papel central de la Organización Mundial de la Salud: Día mundial de la salud (7 de abril), malaria (25 de abril), SIDA (1 de diciembre), tuberculosis (24 de marzo) o del síndrome de Down (21 de marzo) y los minusválidos (3 de diciembre).

4. Educación de calidad inclusiva y permanente con acciones del Fondo de las Naciones Unidas para la Infancia (Unicef) -con embajadores tales como Shakira, Mebarak o Leo Messi- y proyectos sobre niños en la calle y proyectos educativos con la Unesco.

5. Igualdad de género luchando contra la mutilación genital de las jóvenes ( 6 de febrero) o la violencia contra las mujeres ( 25 de noviembre).

6. Agua limpia, saneamiento y restauración de acuíferos sobre todo con el Día Mundial del Agua el 22 de marzo.

7. Energía asequible y no contaminante con una pluralidad de proyectos de energías renovables impulsados por el Banco Mundial y otros bancos regionales de desarrollo en un año, el 2016, en que se han cumplido 40 años de la catástrofe de Xernobil que dejó unos 4.000 muertos, con un coste que se ha estimado en 600.000 millones de dólares poniendo, además, en tela de juicio la energía nuclear.

8. Trabajo decente y crecimiento económico en pro de un trabajo seguro y saludable (28 de abril) o, incluso, justicia social (20 de febrero) impulsados por la Organización Internacional del Trabajo (OIT). 
9. Industria, innovación e infraestructuras con el impulso de la Organización de las $\mathrm{Na}$ ciones Unidas para el Desarrollo Industrial (ONUDI) y la colaboración de, incluso, organismos del sector privado como el Forum Económico Mundial de Davos.

10. Reducción de las desigualdades que son una gran preocupación del Programa de las Naciones Unidas para el Desarrollo (PNUD) que va evaluando los indicadores de desarrollo humano.

11. Ciudades y comunidades sostenibles. En el 2016 se han desarrollado muchas reuniones preparatorias y, sobre todo, los trabajos conducentes a la conferencia Habitat 3 , celebrada en Quito del 17 al 20 de octubre con 40.000 participantes, que ha dejado sobre la mesa una importante agenda urbana, en la que el Director General de la Conferencia sobre Vivienda y Desarrollo Urbano Sostenible (Joan Clos) ha dicho que confiaba en que tendría más implementación por los Gobiernos y autoridades municipales que la de Habitat 2 (Estambul, 1996). La Agenda Urbana aprobada en Quito propone dar respuesta a los problemas urbanísticos, tecnológicos, de inclusión, de medio ambiente en las ciudades como consecuencia de la presión de las ONG y de grupos sociales marginados e indígenas que denuncian la especulación inmobiliaria, los desalojos y la escasa atención de los poderes públicos a los asentamientos informales. La cita de Quito fue acompañada de una Contraconferencia celebrada en la Universidad Central de Ecuador y en la que los antisistema y las poblaciones indígenas pusieron de relieve -con manifestaciones- lo poco ambiciosos que son los Gobiernos para solucionar los problemas urbanos y los problemas de desalojo que se producen.

12. Producción y consumo responsables: el Día Internacional de las Cooperativas, celebrado en julio, puso de relieve lo difícil que se hace «objetivar» este ODS por mucho que en la 28 sesión del Foro de Cooperación Económica Asia Pacífico (APEC) celebrada en Lima (19-20 de noviembre) se hablara de «crecimiento de calidad con desarrollo humano" contraponiéndolo al solo derivado de políticas monetarias expansivas sin avanzar en reformas estructurales.

13. Acción por el clima en que se empezó a desplegar la Agenda de París aprobada por la 21 Conferencia de las Partes de la Convención de las Naciones Unidas sobre el Cambio Climático de diciembre de 2015 (COP21), firmándose por 165 países el correspondiente acuerdo en Nueva York el 22 de abril y llegándose a su puesta en vigor el 4 de noviembre, al haber recibido la ratificación de 55 países (entre ellos China y Estados Unidos) que representan más del 55 por 100 de las emisiones mundiales. En la COP22 celebrada en Marrakech no se consiguieron, sin embargo, avances en la financiación de la lucha contra el cambio climático pese al llamamiento de la Organización Meteorológica Mundial (OMM) denunciando el calentamiento del planeta y los daños colaterales y catástrofes humanitarias que tal calentamiento suscita.

14. Vida submarina, preservación de océanos y mares. El Grupo E15 de la UNCTAD se está ocupando de la pesca sostenible, de las especies migratorias y de la pesca ilegal. El Día Mundial de los Océanos (8 de junio) mostró, además, preocupación por cuestiones de transporte marítimo y turismo estudiadas por la UNCTAD.

15. Recuperación de ecosistemas y preservación de biodiversidad. Las acciones más destacadas se han referido a la lucha contra la desertificación y la sequía (17 de junio) y la protección de la biodiversidad (22 de mayo). $D$ 
16. Paz, justicia e instituciones sólidas. Pese a los años transcurridos desde que las Naciones Unidas pusieron en marcha sus operaciones de paz, siguen existiendo conflictos regionales que generan muchos refugiados y desplazados a los que el Alto Comisariado de las Naciones Unidas para los Refugiados (ACNUR) no puede dar respuesta adecuada. EI PNUD ha lanzado actuaciones contra la corrupción y las violaciones de los derechos humanos en países como Sudáfrica, Kenia y Nigeria pero, como señala Transparencia Internacional, el tema de la corrupción tiene carácter universal y es difícil de combatir (Día Internacional Contra la Corrupción el 9 de diciembre) teniendo en cuenta los tráficos ilícitos, la financiación del terrorismo, la debilidad de la justicia en Estados fallidos y la dificultad de hacer avanzar la democracia en ciertos países (15 de septiembre). Muchos programas de cooperación al desarrollo tratan hoy de crear instituciones sólidas para mejorar la gobernanza en los países en desarrollo.

17. Alianzas para lograr los ODS con medios suficientes. Este $17^{\circ}$ ODS es el que debería impulsar la cooperación internacional al desarrollo y la colaboración entre todas las organizaciones internacionales para adecuar sus reglas y para movilizar recursos en línea con las propuestas marcadas por la Agenda para el Desarrollo en todos sus aspectos: comercio, financiación, adecuación de la gobernanza mundial, reforma de los organismos internacionales a tal fin, eficacia de la ayuda, superación de la ayuda ligada, etcétera.

Se espera que Antonio Guterres, que asume la Secretaría General de las Naciones Unidas en enero de 2017, en substitución de Ban Ki Moon, lleve a cabo una acción dinámica para impulsar el trabajo de los órganos principales de las NNUU y ejerza un liderazgo ante las agencias y las conferencias del sistema de las Naciones Unidas para hacer avanzar los ODS hacia las metas propuestas.

\section{La marcha de la integración europea}

La Unión Europea finaliza, en 2016, bajo presidencia rotatoria neerlandesa en el primer semestre y eslovaca en el segundo, con las dudas con las que comenzó tras la presidencia luxemburguesa del segundo semestre de 2015 pero con un problema añadido de gran importancia: el deseo del 51,8 por 100 de los británicos, convocados a referéndum imprudentemente (por razones internas de partido por el que fue su premier Cameron) el 23 de junio, de abandonar la UE (el conocido como brexit) a pesar de que el Gobierno de Cameron había obtenido una serie de «suavizaciones» del acervo comunitario, según sus pretensiones, en el Consejo Europeo de 18-19 de febrero (competitividad, gobernación económica y soberanía no profundizando en la integración y limitación a migraciones) si votaban por quedarse.

El trío presidencial, enero 2016/junio 2017, se había planteado, en su documento de 3 de diciembre de 2015, al final de la presidencia luxemburguesa del segundo semestre de 2015, una agenda ambiciosa para las presidencias neerlandesa, eslovaca y maltesa con cinco pilares en los que se estimaba que la UE debería avanzar respetando, lógicamente, los principios de subsidiariedad, proporcionalidad, simplicidad, transparencia, coherencia y respeto a los derechos fundamentales:

1. Crecimiento integrador, inteligente y sostenible con aspectos tales como la mejora y avance en la Unión Económica y Monetaria de acuerdo con el Informe de los cinco presidentes de 2015, empleo verde, fiscalidad, etcétera. 
2. Una UE que empodere y proteja a todos los ciudadanos: educación, mujeres, sanidad...

3. Hacia una unión de la energía con una política climática respetuosa de lo acordado en la COP21 de París de finales de 2015.

4. Unión de libertad, seguridad y justicia: migraciones irregulares, reubicaciones, reasentamientos, sistema común de asilo, agenda europea de seguridad, eficacia del Sistema Schengen y Frontex, acuerdos con países limítrofes periféricos a este efecto, etcétera.

5. La UE como actor fuerte a nivel mundial: aspectos comerciales y políticos, y capacidad para impulsar los valores europeos en países que no los respeten.

La Comisión Juncker remaba en la misma dirección, estableciendo prioridades para 2016 en la creación de empleo, crecimiento, inversiones estratégicas (Plan Juncker), mercado único digital (limitación roaming) unión de la energía, cambio climático, mercado interior, una Unión Económica y Monetaria más profunda, negociación del TTIP, derechos fundamentales y derechos humanos, migraciones, la UE como actor internacional más potente y transformación democrática.

El desbordamiento del número de inmigrantes y refugiados que ha presionado para entrar en la UE desde países vecinos en conflicto (Irak, Siria, Libia, etcétera) y la cuestión de un posible futuro brexit, así como el persistente problema de la permanencia de Grecia en la eurozona, las diferencias sobre la relación con la Rusia de Putín o con la Turquía de Erdogán (sobre todo tras el fracasado alzamiento militar contra Erdogán del 15 de julio y la posterior ingente represión) o la oposición popular contra los acuerdos con Canadá (CETA) y con Estados Unidos (TTIP) han obligado a que los Consejos Europeos que se han celebrado y los propios trabajos del Consejo de
Ministros y de la Comisión Europea se vieran forzados a abordar temas distintos a los inicialmente programados.

En cuanto al inquietante brexit, la premier Theresa May (elegida para liderar el partido conservador británico el 30 de junio, después de la renuncia de Cameron tras el fiasco de su referéndum ganado por los partidarios del brexit con un 51,8 por 100 , pero con Escocia y Gibraltar votando en contra de la salida) anunció el 5 de octubre que solicitará el inicio del proceso de separación de la UE a finales de marzo del 2017, presentando la activación del artículo 50 del Tratado de Lisboa. Como una Alta Corte de Justicia británica ha fallado que ello debe pasar por el Parlamento de Westminster (tras el recurso presentado por Gina Miller y Dier Tozetti dos Santos en base al contenido de la European Communities Act de 1972) y en él, a finales de 2016, hay mayoría anti brexit y partidario del Remain, la situación resulta compleja pues hay millones de firmantes solicitando que se rehaga el referéndum.

Parece ser, además, que la propia Reina Isabel ha recordado a la primera ministra que casi la mitad de sus súbditos están en contra del brexit y ha expresado sus dudas sobre si se va a negociar un brexit duro o blando y con permanencia o no en el mercado europeo único y la unión aduanera, sobre el impacto que la salida pueda tener sobre la City como plaza financiera, sobre la actividad aseguradora y sobre los principales sectores industriales, impacto sobre la inversión extranjera, inflación, empleo, plazos o no en que se produciría la transición y la relación que habrá con el resto del continente y el resto del mundo.

Teniendo en cuenta que la campaña secesionista para salir de la UE estuvo llena de engaños de los antieuropeos cara al referéndum $\triangleright$ 
del 23 de mayo y que el coste será muy elevado, así como el hecho de que el antiguo alcalde de Londres, antieuropeo y poco diplomático ministro de Asuntos Exteriores, Boris Johnson, no tenga una hoja de ruta sobre lo que quiere conseguir en la negociación de salida y el propio gabinete esté dividido sobre si seguir adelante con el propio proceso de separación y con lo que debe aceptarse del mercado único (por ejemplo, la libre circulación de trabajadores comunitarios) ha hecho que el negociador de la Comisión para el brexit, el excomisario Barnier y el del Parlamento Europeo Guy Verhofstadt, haya insistido en que la UE defenderá a ultranza el acervo europeo sin aceptar un «brexit blando» y que el proceso debe estar finiquitado antes de las elecciones al Parlamento Europeo de 2019. El 23 de noviembre, el Canciller del Exchequer Philip Hammond pronosticó que con el brexit se producirá un «agujero presupuestario del orden de 122.000 millones de libras que forzará a ir al endeudamiento, que superará el 90 por 100 del PIB en 2018 tras una caída de ingresos por la disminución de la actividad económica derivada de la incertidumbre creada por el abandono de la UE y por la necesidad de bajar impuestos y gastar en infraestructuras, suavizando la austeridad y aumentando gastos sociales con el fin de evitar huelgas y conflictos que aún agravarían más la incertidumbre actual».

En el plano monetario, la UE ha registrado el avance de que, desde el 1 de enero de 2016, los países del euro tienen un Mecanismo Único de Resolución para gestionar las crisis de entidades financieras que no sean viables con coste mínimo para los contribuyentes y la economía real. Con ello se da un paso más de lo que ha sido el Mecanismo
Único de Supervisión gestionado por el BCE y las autoridades nacionales de supervisión, así como un Consejo de Supervisión. Con el Mecanismo Único de Resolución se ha completado la supervisión que, a partir de 2010, se inició con la Autoridad Bancaria Europea, la Autoridad Europea de Seguros y Pensiones de Jubilación y la Autoridad Europea de Valores y Mercados y la Junta Europea de Riesgo Sistémico.

El Mecanismo Único de Resolución será financiado por las propias entidades financieras que irán contribuyendo con el 1,1 por 100 de sus pasivos hasta dotarlo, en 8 años, de 55.000 millones de euros de forma progresiva, en base a un acuerdo intergubernamental y a un sistema de transferencias desde las autoridades nacionales.

Con la puesta en marcha de los Mecanismos de Supervisión, fijando los requisitos de capital de las entidades financieras y los montos de liquidez según los perfiles de riesgo, y creado el mecanismo de Resolución, el próximo paso para perfeccionar la Unión Monetaria Europea será la creación de un Fondo Europeo de Garantía de Depósitos.

El 8 de marzo los ministros de Economía dieron un paso adelante respecto al intercambio de información fiscal entre los Estados miembros, pero las reticencias de Irlanda a recuperar de Apple 13.000 millones de euros por ayudas fiscales recibidas, pone de manifiesto lo difícil que está resultando avanzar hacia la unión fiscal europea y siquiera avanzar hacia estándares mínimos de tributación.

Grecia ha continuado siendo la «oveja negra» de la eurozona al adoptar el Gobierno de Tsipras medidas que van en contra de las medidas de ajuste que la Comisión, el BCE y el FMI consideraban necesarias para abrirle el tercer rescate. Grecia se propone aumentar las $\triangleright$ 
pensiones y otras medidas que van a disparar el déficit excesivo, que no es, por cierto, patrimonio exclusivo de Grecia, pues el comisario Moscovici ha puesto de relieve que además de Grecia están en déficit excesivo e incumplen el Pacto de Estabilidad y Crecimiento: Italia (que se ve agravado por el rescate del Monte dei Paschi di Siena a finales de diciembre), España, Portugal, Bélgica, Chipre, Lituania, Eslovenia y Finlandia.

El tema de los refugiados y emigrantes que tratan de asentarse en la UE ha marcado el calendario europeo durante todo el 2016 y ha estimulado movimientos nacionalistas y populistas antieuropeos en una serie de países, poniendo en peligro la libre circulación de trabajadores y la libre circulación en la zona Schengen. Los intentos de asignación de llegados impulsados por Juncker no han dado resultados (9 de mayo) como tampoco se ha conseguido gran cosa en el acuerdo con Turquía para que frenara el aluvión de inmigrantes y refugiados. Con estos fracasos, el Mediterráneo se ha convertido en un auténtico cementerio de africanos y asiáticos que trataban de llegar a Europa con pateras movilizadas por mafias traficantes de personas.

En el plano económico interno, el desempleo en Europa comenzó en 2016 con el 10,1 por 100 , si bien con diferencias notables entre países (en España se estaba al 19,9 por 100). Ante esto, el Plan Juncker de inversiones estratégicas, que ha visto ampliada su cuantía en 2016, se propone conseguir hacer avanzar a las economías europeas pues, si esto no se consigue, los Gobiernos europeos irán perdiendo apoyo popular como se ha visto con la caída de Renzi en Italia -tras su intento de reforma constitucional el 4 diciembre- y su sustitución por Gentiloni (11 de diciembre) y con la dimisión de Valls por Cazaneuve, en diciembre, tras el anuncio del presidente Hollande de que no intentará la reelección a la presidencia francesa en 2017. La canciller Merkel ha llegado a perder algunas elecciones regionales alemanas.

En el plano de las relaciones con la OMC y las medidas comerciales autónomas, hay que mencionar la condena de las subvenciones europeas a Airbús, el comienzo de la transposición por la UE de los acuerdos de la X Conferencia Ministerial de la OMC en Nairobi en 2015 y los avances en la negociación del Acuerdo Plurilateral de Bienes Medioambientales, así como los avances en la negociación del Acuerdo de Servicios (TISA) y, por otra parte, el mantenimiento de medidas comerciales contra China (por dumping) y contra Rusia (prolongación de sanciones en diciembre por la ocupación de Crimea y el apoyo a los secesionistas de la parte este de Ucrania).

Entre los acuerdos firmados en 2016 por la UE merecen destacarse los firmados con Canadá (CETA), Ecuador y Cuba. El de Ecuador se he concretado en el acceso del país al Acuerdo Comercial Multipartes con Perú y Colombia. El Acuerdo de Diálogo Político y Cooperación con Cuba, firmado el 12 de diciembre, ha comportado la revocación de la Posición Común sobre Cuba impuesta en 1996 y un Programa Indicativo, dotado con 85 millones de euros, de ayuda para 20142020. Con este acuerdo la UE renormaliza las relaciones con la Cuba castrista y se adelanta a lo pactado por Obama con Raúl Castro al restablecer relaciones diplomáticas en 2015, pero sin romper el bloqueo económico y comercial iniciado por Eisenhower en 1960-1961 y reforzado por la Ley para la libertad y la solidaridad democrática (Helms-Burton) de 1996, pese al requerimiento efectuado, el 27 de octubre de 2016, al respecto, por 191 de los 193 miembros de las Naciones Unidas. 
El Acuerdo Económico y Comercial Global de la UE con Canadá (CETA) fue firmado el 30 de octubre de 2016 tras un accidentado proceso de aceptación (con un curioso veto final de la región belga de Valonia) y una oposición de grupos antisistema contra este acuerdo y con el TTIP con Estados Unidos aún en negociación (y que es, por cierto, bastante similar al firmado con Canadá pero que Trump parece que quiere desestimar y que ha concitado una gran oposición callejera y de las ONG). Este «Comprehensive Economic and Trade Agreement» con Canadá tiene 13 capítulos desarrollados en 1598 páginas y es el mayor pacto bilateral negociado por la UE. Prevé la supresión de la mayoría de aranceles sobre productos industriales en 7 años, algunas reducciones de barreras sobre productos agrarios, si bien la UE podrá mantener sus precios de entrada, el acceso de las empresas de la otra parte a los contratos públicos, un incremento de la cooperación en materia de regulación, la protección de innovaciones y productos tradicionales (con protección de 145 denominaciones de origen), la apertura del comercio de servicios (financiación, telecomunicaciones, energía, transporte marítimo), facilitación de desplazamientos profesionales, promoción de inversiones y creación de un tribunal arbitral para solución de litigios (el tema, por cierto, más criticado por los grupos opuestos al CETA y al TTIP pese a ya existir un mecanismo similar en el Banco Mundial y en la Cámara de Comercio Internacional), la garantía de ampliar la cooperación en el futuro y la protección de democracia, consumidores y medio ambiente (entre ellos el mantenimiento de las restricciones europeas a los alimentos genéticamente modificados). Por tratarse de un acuerdo mixto, incluyendo competencias nacionales de los Estados miembros de la UE, el CETA solo ha empezado a aplicarse provisionalmente en la parte en la que existe competencia europea, quedando el resto a la espera de las ratificaciones del Parlamento canadiense y de los Parlamentos de los países europeos que, seguramente, no resultará fácil.

En el plano del comercio global cabe mencionar que la UE ha empezado a discutir con los 96 países de África, Caribe y el Pacifico $(A C P)$ el diseño de lo que debería ser la cooperación y el comercio entre los miembros de la UE y los 79 miembros del Grupo ACP, viendo si debe seguirse con un Convenio de Cotonou renovado post 2020 , con, además, un nuevo Fondo Europeo de Desarrollo (tras el $11^{\circ}$ actual) o si se elige otro camino de cooperación aprovechando las lecciones de los anteriores convenios de Lomé de 1975 a 2000 y del actual Convenio de Cotonou en vigor desde el año 2000, teniendo en cuenta, por otra parte, el compromiso de la UE con los Objetivos de Desarrollo Sostenible y la Agenda Internacional de Desarrollo.

En el plano político, la UE está expectante en relación a las ideas de Trump de retirar progresivamente sus tropas de Europa. Ante ello el Secretario General de la OTAN, Jens Stoltenberg, ha recordado a los países europeos que deberían aumentar su esfuerzo de defensa.

\section{España en el sistema internacional}

El 1 de enero de 2016 se cumplió el 30 aniversario del ingreso de España a la entonces Comunidad Europea. España representa en este momento el 1,7 por 100 del comercio mundial de mercancías ( $18^{\mathrm{a}}$ posición mundial) y el 2,5 por 100 del comercio mundial $D$ 
de servicios ( $11^{\mathrm{a}}$ posición mundial), siendo la tercera potencia turística, con un desarrollo espectacular de este sector por el turismo derivado hacia España por los conflictos y el terrorismo en el Mediterráneo.

La exportación de mercancías ha tenido un comportamiento muy satisfactorio (crecimiento del 5,8 por 100 ) bien que con una ligera inflexión a finales del año por el menor crecimiento del comercio global.

Con estos parámetros, el PIB español ha crecido en el 2016 por encima del 3 por 100, que es un resultado extraordinario si se compara con otros miembros de la OCDE. El presidente del BCE saludaba en Madrid (30 de noviembre) que el desempleo español hubiera bajado del 24 al 19 por 100 gracias a la reforma financiera y la laboral, pero alertaba sobre los problemas que cara al futuro van a representar el envejecimiento de la población y la caída de la productividad.

En el 2016, España permaneció, desde la fallida investidura de Gobierno tras las elecciones del 20 de noviembre de 2015 hasta la difícil investidura de un nuevo Gobierno Rajoy el 3 de noviembre de 2016 (tras unas segundas elecciones el 26 de junio), con un Gobierno solamente en funciones, lo cual no ha sido obstáculo para que Rajoy participara en la COP22 de Marrakech (aunque sin intervenir) y que España haya jugado su papel en el Consejo de Seguridad de las Naciones Unidas en el periodo 2015-2016, primero con el ministro José Manuel García Margallo y, tras el cambio de Gobierno Rajoy, con el hasta entonces Embajador Representante Permanente ante la UE, Alfonso Dastis. El propio Rajoy ha presidido el Consejo de Seguridad con la difícil papeleta de la crisis de Alepo y del asesinato del embajador ruso en Turquía, a finales de diciembre.
A lo largo de estos meses, el ministro de Economía en funciones, Luis de Guindos, ha tenido que luchar en el Eurogrupo y en el Ecofin para que la Comisión Europea no aplicara sanciones a España por el procedimiento de déficit excesivo (decisión sobre Portugal y España del 7 de julio). Por otra parte, la prima de riesgo española ha llegado a caer por debajo de los 100 puntos (por primera vez desde abril de 2015) lo cual ha permitido que el Tesoro se financiara a tipos de interés bajos e inferiores al coste de los préstamos del Mecanismo Europeo de Estabilidad (MEDE). Esto demuestra que los mercados reconocen los esfuerzos estructurales llevados a cabo por España y su estabilidad pese al reto del independentismo catalán, al elevado desempleo $(19,6$ por 100$)$ y pese al déficit fiscal por encima de lo establecido por la UE en el Tratado de Maastricht y al Pacto de Estabilidad y Crecimiento (4,6 por 100 en 2016) y una deuda que se sitúa en una cifra próxima al 100 por 100 del PIB después de que el Tesoro se haya tenido que financiar en 2016 con 35.000 millones de euros, haciendo a España más vulnerable cara a los previsibles futuros aumentos de los tipos de interés que han empezado ya en Estados Unidos.

Tras la entrada en vigor de las nuevas cuotas del FMI, la cuota asignada a España ha avanzado hasta el 2 por 100 del total, muy cercana a la mínima exigida a los países de menor peso, entre los que pueden designar directamente un director ejecutivo (Rusia con 2,6 por 100 y Arabia Saudí con 2,02: ver supra). En su misión-consulta del artículo IV del FMI, los expertos de esta institución de Bretton Woods alabaron la recuperación sólida que se está produciendo en España, al igual que lo hicieran los técnicos de la OCDE certificando que los desequilibrios se están corrigiendo gracias a las reformas estructurales $\triangleright$ 
lanzadas, pero llamando la atención sobre la necesidad de una revisión de la financiación autonómica y un mayor énfasis en la lucha contra el desempleo y el empleo precario.

En el 2016 España ha entrado en el Banco Asiático de Inversión en Infraestructuras, con sede en Pekín y una suscrición de capital del 1,7 por 100 de su total, lo cual debe servir para que las empresas constructoras españolas sigan presentándose y ganando concursos internacionales como SACYR en las obras del Canal de Panamá (inauguración de la ampliación el 26 de junio), gestión de autopistas por Abertis, AVE Meca-Medina, en que el 21 de noviembre se firmaba el acuerdo sobre fechas y sobrecostes entre el Consorcio español Alta Velocidad Meca Medina (Renfe, ADIF, Talgo y hasta doce empresas españolas y dos saudíes) y su contraparte saudí que hace prever que el proceso del AVE de los peregrinos o del desierto culminará satisfactoriamente.

En relación al CETA, firmado y en aplicación parcial, España ha conseguido que Canadá le reconozca y proteja 26 denominaciones de origen que incluyen aceites, quesos, turrones, embutidos, jamón y cítricos.

No pueden acabar estas referencias sobre España en el sistema internacional sin mencionar la importancia que el brexit presenta para la economía española por la importancia del comercio recíproco, por los españoles que trabajan en el Reino Unido y los británicos jubilados en España, así como por la circunstancia de que el 96 por 100 de los gibraltareños votaron en el Referéndum del brexit por no salir de la UE.

\section{Bibliografía}

[1] ALCAZAR, J. (2016). TTIP: la gran amenaza del capital. Sevilla: Foca.
[2] BERNANKE, B. (2016). El valor de actuar. Barcelona: Planeta.

[3] COMIN, F. (2015). Las crisis de la deuda soberana en España 1500-2015. Madrid: Catarata.

[4] CUSOLITO, A.P.; SADAFI, R. y TAGLIONI, D. (2016). Inclusive Global Value Chains: policy options for Small and Medium Enterprises Low-income countries. World Bank and OECD Group.

[5] DE GUINDOS, L. (2016). España amenazada: de como evitamos el rescate y la economía recuperó el crecimiento. Barcelona: Península.

[6] FORD, M. (2016). El auge de los robots: la tecnología y la amenaza de un futuro sin empleo. Barcelona: Paidós.

[7] FUNDACIÓN SEMINARIO DE INVESTIGACIONES PARA LA PAZ (2015). Impacto de la crisis en el proyecto europeo. Zaragoza: Mira eds.

[8] GALLEGOS, R. (2016). ¿Cuándo se jodió Venezuela? Barcelona: Deusto.

[9] GAMBLE, A. (2016). Can the Welfare State survive? Bognor Regis: John Wiley.

[10] GARCÍA DURÁN, P. y MILLET, M. (coords) (2016). Different Glances at EU Trade Policy. Barcelona: CIDOB-Europe for Citizens.

[11] GARCÍA MARGALLO, J.M. y EGUIDAZU, F. (2016). Europa y el porvenir: cómo preservar y fortalecer el modelo europeo de bienestar. Barcelona: Planeta.

[12] GIL, J. (2016). Suspiros de Europa: España, Turquía y la crisis de la UE. Madrid: Sial Pigmalión.

[13] GRANELL, F. (2016). Los retos de la Cuarta Revolución Industrial. Barcelona: Real Academia de Ciencias Económicas y Financieras, Acto Académico en San Millán de la Cogolla.

[14] GRANT, A. (2016). Originals: How non-conformists change the World. London: WH Allen, Penguin Books.

[15] HAMILTON, D. y PELKMANS, J. (edits) (2015). Rule Maker or Rule Takers?: Exploring the TTIP. London: Bowman and Little field.

[16] KAISER, A. y ALVAREZ, G. (2016). El engaño populista. Barcelona: Deusto.

[17] KING, M. (2016). The end of Alchemy. Money, Banking and the Future of the Global Economy. London: Norton. 
[18] KISSINGER, H. (2016). Orden Mundial: Reflexiones sobre el carácter de los países y el curso de la historia. Barcelona: Debate.

[19] LAMO DE ESPINOSA, J. (2016). El agua en el Mundo-El Mundo del agua (El agua en un mundo global y bajo el cambio climático). Barcelona: Real Academia de Ciencias Económicas y Comerciales.

[20] LAMPTON, D.M. (2015). Adónde va China: los planes de futuro de los dirigentes chinos. Barcelona: Stella Maris.

[21] MANGUSON, L. y STRATH, B. (2016). A Brief History of Political Economy.Tales of Marx, Keynes and Hayek. London: Edward Elgar.

[22] MASON, P. (2016). Postcapitalismo: hacia un nuevo futuro. Barcelona: Paidós.

[23] MORELL, M. y HARLOW, B. (2016). La gran guerra de nuestro tiempo: de Al Qaeda a ISIS. Barcelona: Crítica.

[24] NAPOLEONI, L. (2016). Traficantes de Personas. Barcelona: Paidós.

[25] OBEMAIER, F. y OBEMAYER, B.(2016). Los Papeles de Panamá, el club mundial de los evasores de impuestos. Barcelona: Península.

[26] PALACIO, V. (2016). Después de Obama: Estados Unidos en tierra de nadie. Madrid: Catarata.

[27] PAULSON Jr., H.M. (2016). Negociando con China: la nueva potencia mundial al descubierto. Barcelona: Deusto.

[28] PHILLIPS, T. (editor) (2016). Bajo el yugo neoliberal: crisis de la deuda y disidencias en las periferias europeas. Madrid: Akal.

[29] POU, V. (2016). ¿Hacia una deconstrucción de la Unión Europea? La Europa del futuro. Barcelona: Milenio.

[30] PUIGDOMENECH, P. (2016). Desafíos del futuro: doce dilemas y tres instrumentos para afrontarlos en el duodécimo milenio. Barcelona: Crítica.
[31] SALA, M. y MINGUELL, F.X. (2016). «Política Monetaria no convencional: los programas de compra de activos del Banco Central Europeo". Boletín de Información Comercial Española, $\mathrm{n}^{\circ}$ 3081, noviembre, pp. 17-30.

[32] SANDERS, B. (2016). Discurso sobre la codicia de las grandes empresas y el declive de la clase media. Barcelona: Malpaso.

[33] SCHNAPPER, P. (2016). Le Royaume Uni doit-il sortir de l'UE? Paris: La Documentation Française.

[34] SCHWAB, K. (2016). La Cuarta Revolución Industrial. Barcelona: Debate.

[35] STEIL, B. (2016). La batalla de Bretton Woods: Keynes, White y cómo se fraguó el nuevo orden mundial. Barcelona: Deusto.

[36] STIGLITZ, J.E. (2016). El Euro: cómo la moneda común amenaza el futuro de Europa. Madrid: Taurus.

[37] TAIBO, C. (2016). Colapso: capitalismo terminal, transición ecosocial, ecofascismo. Madrid: Catarata.

[38] TAIBO, C. (2016). Para entender el TTIP. Madrid: Catarata.

[39] TAMAMES, R. (2016). Frente al Apocalipsis del clima. Barcelona: Profit.

[40] TIROLE, J. (2016). Economie du bien commun. Paris: Presses Universitaires de France.

[41] TOLEDO, A. (2016). La sociedad compartida. Barcelona: Península.

[42] VAROUFAKIS, Y. (2016). ¿Y los pobres, sufren lo que deben? Cómo hemos llegado hasta aquí y por qué necesitamos un plan $B$ para Europa. Barcelona: Deusto.

[43] VELASCO, R. (2016). Economistas: oficio de profetas. Madrid: Catarata.

[44] WALLWITZ G.VON (2016). Mr. Smith y el Paraíso. Barcelona: Acantilado.

[45] WORLD ECONOMIC FORUM (2016). The Future of Jobs: Employment, Skills and Workforce Strategy for the Fourth Industrial Revolution. Geneva. 


\section{SUSCRIPCIÓN ANUAL}

\begin{tabular}{|c|c|c|c|}
\hline \multicolumn{3}{|c|}{ BOLETíN ECONÓMICO DE INFORMACIÓN COMERCIAL ESPAÑOLA (12 NÚMEROS) } \\
\hline & $\begin{array}{c}\text { ESPAÑA } \\
1 \text { año }\end{array}$ & $\begin{array}{c}\text { UNIÓN EUROPEA } \\
1 \text { año }\end{array}$ & $\begin{array}{c}\text { RESTO DEL } \\
\text { MUNDO } \\
1 \text { año }\end{array}$ \\
\hline SUSCRIPCIÓN & $65,00 €$ & $85,00 €$ & $85,00 €$ \\
\hline $\begin{array}{c}\text { Gastos de envío } \\
\text { España }\end{array}$ & $5,76 €$ & $24,36 €$ & $30,00 €$ \\
\hline $\begin{array}{c}\text { Más 4\% de IVA. } \\
\text { Excepto Canarias, Ceuta y Melilla }\end{array}$ & $2,83 €$ & & $115,00 €$ \\
\hline TOTAL & $73,59 €$ & $109,36 €$ & \\
\hline
\end{tabular}

\section{EJEMPLARES SUELTOS}

\section{BOLETÍN ECONÓMICO DE INFORMACIÓN COMERCIAL ESPAÑOLA}

\begin{tabular}{|c|c|c|c|}
\hline & $\begin{array}{l}\text { ESPAÑA } \\
1 \text { ejemplar }\end{array}$ & $\begin{array}{c}\text { UNIÓN EUROPEA } \\
1 \text { ejemplar }\end{array}$ & $\begin{array}{l}\text { RESTO DEL } \\
\text { MUNDO } \\
1 \text { ejemplar }\end{array}$ \\
\hline NÚMERO SUELTO & $7,00 €$ & $9,00 €$ & $9,00 €$ \\
\hline $\begin{array}{l}\text { Gastos de envío } \\
\text { España }\end{array}$ & $0,48 €$ & $2,03 €$ & $2,50 €$ \\
\hline $\begin{array}{l}\text { Más } 4 \% \text { de IVA. } \\
\text { Excepto Canarias, Ceuta y Melilla }\end{array}$ & $0,30 €$ & & \\
\hline TOTAL & $7,78 €$ & $11,03 €$ & $11,50 €$ \\
\hline \multicolumn{4}{|l|}{ BOLETÍN ECONÓMICO D } \\
\hline & $\begin{array}{l}\text { ESPAÑA } \\
1 \text { ejemplar }\end{array}$ & $\begin{array}{c}\text { UNIÓN EUROPEA } \\
1 \text { ejemplar }\end{array}$ & $\begin{array}{c}\text { RESTO DEL } \\
\text { MUNDO } \\
1 \text { ejemplar }\end{array}$ \\
\hline $\begin{array}{l}\text { NÚMERO SUELTO } \\
\text { EXTRAORDINARIO }\end{array}$ & $12,00 €$ & $15,00 €$ & $15,00 €$ \\
\hline Gastos de envío España & $0,48 €$ & $2,03 €$ & $2,50 €$ \\
\hline $\begin{array}{l}\text { Más } 4 \% \text { de IVA. } \\
\text { Excepto Canarias, Ceuta y Melilla }\end{array}$ & $0,50 €$ & & \\
\hline TOTAL & $12,98 €$ & $17,03 €$ & $17,50 €$ \\
\hline
\end{tabular}

\section{DATOS}

Nombre y apellidos

Empresa

Domicilio

D.P.

N.I.F.

Teléf.

Email
Transferencia a la cuenta de ingresos por venta de publicaciones del Ministerio de Economía, Industria y Competitividad.

IBERCAJA. Calle Alcalá 29. 28014 MADRID (ESPAÑA) CÓDIGO CUENTA CLIENTE: 2085-9252-07-0330598330 CÓDIGO BIC DE IBERCAJA: CAZRES2Z IBAN: ES47 2085-9252-07-0330598330
GOBIERNO DE ESPAÑA
MINISTERIO

DE ECONOMÍA, INDUSTRIA

Y COMPETITIVIDAD
SUBSECRETARÍA

SECRETARÍA GENERAL TÉCNICA

SUBDIRECCIÓN GENERAL

ESTUDIOS, INFORMACIÓN Y PUBLICACIONES

Suscripciones y ventas por correspondencia:

Paseo de la Castellana, 162 9a Planta 28046 Madrid. Teléfono 91603 79 93/97

Suscripciones a través de la página web del Ministerio de Economía, Industria y Competitividad

distribucionpublicaciones@mineco.es 